\title{
Promoting heath in 2012: embracing alternative evaluation designs, working practices and service delivery modes
}

\author{
Diane Crone • Colin Baker
}

Published online: 9 June 2012

(C) Springer-Verlag 2012

An Olympic year brings suspense, the utmost of human endeavour, glory and jubilation, but also tears and disappointment for athletes, spectators and politicians alike (Cashman 2006). This year heralds the return of the Olympic flame to U.K. shores, but with it some profound and deeply testing concerns. Escalating costs of health care, housing and food, in addition to progressive economic decline and attendant austerity measures are challenging the health and quality of life of many communities. Thus, the joy and jubilation of the Olympics and Paralympic Games provides a useful although temporary distraction from the day-to-day concerns of rising unemployment, dwindling access and accessibility to health and public services for governments, policy makers, public health professionals and researchers.

However, just as mega-events bring a range of economic and social issues sharply into focus (Müller 2012), there is a need for the continued scrutiny of health status in our communities, especially in socio-economically deprived and disadvantaged groups. This should be undertaken in combination with the review and evaluation of services for health improvements to ensure that the effects of the current recession are managed and wherever possible restricted. Yet, even the cause for evidenced-based practice in public health is being challenged. Policy makers, researchers and public health professionals have not escaped the clutches of austerity in an era which has witnessed severe cuts to funding for research and public services. As a consequence, there is a pressing need to reconsider alternative ways of working to

D. Crone $(\bowtie) \cdot$ C. Baker

Faculty of Applied Sciences, University of Gloucestershire,

Oxstalls Campus, Oxstalls Lane,

Gloucester GL2 9HW, UK

e-mail: dcrone@glos.ac.uk continue the development of high quality evidence to ensure that practice remains focussed, relevant and applicable to the continued health problems and changing needs of society (Dugdill et al. 2009).

It is against this backdrop that this issue of the Journal of Public Health helps demonstrate the changing health concerns in society, the relevance of partnership and multi-disciplinary working, and the need to explore alternative approaches to service delivery and evaluation. Porzsolt et al. discuss the complexities of differing perspectives within health care and the challenges this presents when considering evidence-based decision making. They highlight the importance of considering individual values in the development of a health-care strategy, a challenging perspective for scientist and clinicians to consider. Akmatov et al. present an example of economic and political upheaval to highlight the scarcity of data on infectious diseases. This draws particular attention to the surveillance and reporting of migrant status, as part of infectious disease examination.

In a timely reminder of the effects of twenty-first century living, Sun et al. investigate the problem with metabolic syndrome and the link to older age and gender differences in a large population study based in the USA. They conclude by making suggestions for alternative approaches for diagnosis and propose a modelling technique to inform future clinical practice. Population focussed studies continue with Attarchi et al. In a professional group that has become of increasing interest to researchers, their article reviews the rate of traffic injuries and related factors. Their finding that accidents are associated with longer working hours is relevant but also concerning for many countries where professional drivers are more than ever facing the prospect of longer working hours to sustain their livelihoods. Szlachta et al. examine those experiencing long-term unemployment in Germany and their perceptions of ability to work. This is highly pertinent given the levels of unemployment are rising in many countries 
and provides insightful and important knowledge for health professionals and government officials across a range of EU countries.

Diniz et al. examine health workers in Brazil in relation to their perceptions of oral health practices in early childhood. Their findings offer some useful and cost effective implications for the education of health workers in this area in order to improve knowledge and inform working practices with parents.

Mental health also receives consideration in two papers in this issue; one involving an evaluation of the arts on prescription intervention from the UK, the other a study of the prevalence of depression in Australia. Crone et al. evaluate the role of art intervention in primary care using a qualitative methodology to provide participants perspectives on the intervention. It concludes by emphasising the potential role of such interventions for public health enhancement and highlights the criticalness of multi-disciplinary approaches to evaluation and delivery of a health care service. In contrast, Butterworth et al. adopt a population cohort design to investigate the prevalence of depression. They examine the distribution of depression and the influence of contrasting measures of socio-economic status, citing individual risk factors including age, gender and marital status as those with the strongest influence. The two papers present an interesting insight into mental health, highlighting the link between depression and socio-economic status and an innovative intervention for the promotion of mental health.

This issue also explores young people, with articles relating to anaemia, pregnancy and childbirth, and student health. Hamad et al. consider the importance of nutrition in adolescents, comparing pregnant and non-pregnant adolescents in the Gaza Strip. Once again, this paper concludes with some useful practical solutions to addressing the prevalence of anaemia and poor nutrition in adolescents. In a study undertaken in Iran, Moudi et al. present a qualitative paper describing the development and validation of an instrument for assessing women's expectations of childbirth services. They conclude that the tool has direct relevance for future policy and practice. The final paper by Saad et al. relates to student health in Nigeria. Student health and the incumbent risk of various chronic and infectious diseases is of interest to many. The article evaluates an intervention programme in HIV-STI risk reduction. Utilizing a randomised controlled field-trial approach, they identify that a peer-led programme was effective for developing knowledge and awareness and in reducing sexual risk behaviour in the population group.

Without doubt, this issue of the Journal of Public Health presents a diverse and interesting range of articles that individually address many of the common issues with which policy makers, researchers and public health professionals are concerned. Particular attention is drawn to interventions addressing continuing and newly developing health problems in society and the diversity of methodologies that can be used to develop knowledge and evidence via multi-disciplinary working practices across the globe (Gilbert 2006; Hatton and Schroeder 2007). This eclecticism demonstrates that public health is increasingly characterised by innovative methods of service evaluation and delivery in collaboration with partners from other health disciplines, medicine, government and education. Multi-disciplinary practice, and research and evaluations that are derived from such collaboration can only serve to furnish us with the necessary evidence to enhance policy and practice (Dugdill et al. 2009). This must be welcomed and encouraged, particularly in light of the pressures on public and private finances. Hence, just as the spirit of the Olympics encourages us to seek mutual understanding, solidarity and a refusal to throw in the towel, alternative ways of working together in public health may provide the key to successful and sustainable policy and practice.

\section{References}

Cashman R (2006) The bitter-sweet awakening: the legacy of the Sydney 2000 Olympic Games. Walla Walla, Petersham, Australia

Dugdill L, Crone D, Murphy, R (2009) Physical activity and health promotion: evidence-based approaches to practice. WileyBlackwell, London

Gilbert T (2006) Mixed methods and mixed methodologies: the practical, the technical and the political. J Res Nurs 11(3):205-217. doi: $10.1177 / 1744987106064634$

Hatton MJ, Schroeder K (2007) Partnership theory and practice: time for a new paradigm. Can J Dev Stud 28(1):157-162

Müller M (2012) Popular perception of urban transformation through mega-events: understanding support for the 2014 Winter Olympics in Sochi. Environ Plan C Gov Policy 30:1-35 